Fixed Point Theory, 20(2019), No. 2, 511-522

DOI: $10.24193 /$ fpt-ro.2019.2.33

http://www.math.ubbcluj.ro/ nodeacj/sfptcj.html

\title{
A DOMAIN-THEORETIC BISHOP-PHELPS THEOREM
}

\author{
ALI HASSANZADEH*, ILDAR SADEQI**,1 AND ASGHAR RANJBARI*** \\ * Department of Mathematics, Sahand University of Technology, Tabriz, Iran \\ E-mail: a_hassanzadeh@sut.ac.ir \\ ** Department of Mathematics, Sahand University of Technology, Tabriz, Iran \\ E-mail: esadeqi@sut.ac.ir \\ *** Department of Pure Mathematics, University of Tabriz, Tabriz, Iran \\ E-mail: ranjbari@tabrizu.ac.ir
}

\begin{abstract}
In this paper, the notion of $c$-support points of a set in a semitopological cone is introduced. It is shown that any nonempty convex Scott closed bounded set has a $c$-support point in a cancellative $b d$-cone under certain condition. We also introduce the notion of $w d$-cone and then we prove a Bishop-Phelps type theorem for $w d$-cones, especially for normed cones, under appropriate conditions. Finally, using of the Bishop-Phelps technique, we obtain a result about the fixed points of a mapping on $s$-cones.
\end{abstract}

Key Words and Phrases: $s$-cone, Scott topology, support point, Bishop-Phelps theorem.

2010 Mathematics Subject Classification: 46N10, 47L07, 54D10.

\section{REFERENCES}

[1] S. Abramsky, A. Jung, Domain theory, In S. Abramsky, D.M. Gabbay, T.S.E. Maibaum (eds.), Handbook of Logic in Computer Science, vol. 3, Clarendon Press, 1994.

[2] C.D. Aliprantis, K.C. Border, Infinite Dimensional Analysis: A Hitchhiker's Guide, 3rd edition, Springer-Verlag, Heidelberg and New York, 2006.

[3] E. Bishop, R.R. Phelps, The support functionals of a convex set, Convexity, Proc. Sympos. Pure Math, Amer. Math. Soc., Providence, 7(1963), 27-35.

[4] M. Fabian et al., Banach Space Theory: The Basis for Linear and Nonlinear Analysis, Springer, 2011.

[5] G. Gierz, K.H. Hofmann, K. Keimel, J.D. Lawson, M. Mislove, D.S. Scott, Continuous Lattices and Domains, vol. 93, Encyclopedia of Mathematics and its Applications, Cambridge University Press, 2003.

[6] J. Goubault-Larrecq, A cone theoretic Krein-Milman theorem, Rapport de Recherche LSV-0818, ENS Cachan, France, 2008.

[7] J. Goubault-Larrecq, Non-Hausdorff Topology and Domain Theory: Selected Topics in PointSet Topology, Cambridge University Press, 2013.

[8] A. Granas, J. Dugundji, Fixed Point Theory, Springer Monographs in Mathematics, Springer, 2003.

[9] K. Keimel, Topological cones: Functional analysis in a $T_{0}$-setting, Semigroup Forum, 77(2008), 109-142.

\footnotetext{
${ }^{1}$ Corresponding author.
} 
[10] K. Keimel, W. Roth, Ordered Cones and Approximation, vol. 1517, Lecture Notes in Mathematics, Springer-Verlag, Berlin, 1992.

[11] J.D. Lawson, Domains, integration and positive analysis, Math. Structures Comput. Sci., 14(2004), no. 6, 815-832.

[12] G. Plotkin, A domain-theoretic Banach-Alaoglu theorem, Math. Structures Comput. Sci., 16(2006), no. 2, 299-311.

[13] W. Roth, Hahn-Banach type theorems for locally convex cones, J. Aust. Math. Soc., 68(2000), no. 1, 104-125.

[14] W. Roth, Separation properties for locally convex cones, J. Convex Anal., 9(2002), no. 1, 301307.

[15] W. Roth, Operator-Valued Measures and Integrals for Cone-Valued Functions, vol. 1964, Lecture Notes in Mathematics, Springer-Verlag, Berlin, 2009.

[16] P. Selinger, Towards a semantics for higher-order quantum computation (expanded version), In Proceedings of the 2nd International Workshop on Quantum Programming Languages, Turku, Finland. TUCS General Publication, (2004), no. 33, 127-143.

[17] R. Tix, Continuous d-Cones: Convexity and Powerdomain Constructions, PhD thesis, Technische Universität Darmstadt, Shaker, Aachen, 1999.

[18] R. Tix, Some results on Hahn-Banach type theorems for continuous D-cones, Theor. Comput. Sci., 264 (2001), 205-218.

[19] R. Tix, K. Keimel, G. Plotkin, Semantic domains for combining probability and nondeterminism, Electron. Notes Theor. Comput. Sci., 222(2009), 3-99.

Received: January 4, 2017; Accepted: April 21, 2017. 
